\title{
AVALIAÇÃO DA SUSTENTABILIDADE DE PROJETOS DE INOVAÇÃO TECNOLÓGICA DESENVOLVIDOS POR EMPRESAS INDUSTRIAIS BRASILEIRAS
}

\section{SUSTAINABILITY ASSESSMENT OF TECHNOLOGICAL INNOVATION PROJECTS DEVELOPED BY BRAZILIAN INDUSTRIAL ENTERPRISES}

\author{
Alysson Andrade Amorim ${ }^{1}$; Hermes de Andrade Junior ${ }^{2}$ \\ ${ }^{1}$ Centro Universitário UNIEURO - Brasília - Brasil \\ alys br@yahoo.com.br \\ ${ }^{2}$ Centro Universitário UNIEURO - Brasília - Brasil \\ respeamb@gmail.com
}

\begin{abstract}
Resumo
Este trabalho analisa projetos de inovação tecnológica desenvolvidos por empresas brasileiras que buscam apoio técnico e financeiro externo. Realizou-se uma revisão bibliográfica para caracterizar a inovação tecnológica na realidade das empresas brasileiras e a importância da sustentabilidade para os seus negócios, considerando os interesses de todos os stakeholders. Foi desenvolvida uma pesquisa exploratória, via estudo de caso, a partir das informações obtidas de 77 projetos aprovados no Edital SENAI SESI de Inovação 2010. As inovações tecnológicas consideradas nos projetos que compõem a amostra escolhida podem envolver a otimização de processos de fabricação, controle de resíduos, melhorias no design de produtos ou desenvolvimento de novas metodologias sociais aplicadas à rotina de trabalhadores das indústrias que possam ser replicáveis nas empresas. Neste artigo levantamos informações gerais, considerando as atividades inovadoras das empresas, dos impactos ambientais e sociais dos projetos e verificamos repercussões na sustentabilidade dessas empresas. Suscita aprofundamento do estudo para elementos mais conclusivos nessa direção.
\end{abstract}

Palavras-chave: sustentabilidade; competitividade; inovação; SENAI/SESI.

\section{Introdução}

A partir dos desafios impostos pelo ambiente globalizado, em que a capacidade de inovar assume caráter decisivo nas relações econômicas entre empresas e entre países, a gestão da inovação tecnológica transforma-se em vasto campo de atuação, especialmente para o Brasil. No período em que as políticas industriais estavam baseadas na substituição de importações, a indústria brasileira ganhou musculatura.

Um tema constante que tem permeado os estudos da gestão da inovação é a necessidade de uma estratégia que proporcione a melhoria do desempenho de inovações tecnológicas consideradas 
viáveis, seja considerando apenas os recursos da organização ou quando se busca recursos externos para inovar. Quando se opta por recursos externos, é importante que haja uma estratégica para os programas de desenvolvimento de inovação tecnológica, alinhada à estratégia global da organização. Este alinhamento permitirá identificar as oportunidades existentes e a melhor forma de aproveitá-las.

Existe um razoável consenso de que o esforço da indústria brasileira em inovação tecnológica é ainda insuficiente ou está abaixo do que poderia ser desejado para uma economia que pretende alcançar taxas de crescimento mais altas e inserir-se de forma mais virtuosa no comércio internacional.

O interesse pelo assunto surge da participação do primeiro autor como integrante da equipe que coordena o Edital SENAI SESI de inovação, composta por especialistas do SENAI - Serviço Nacional de Aprendizagem Industrial e do SESI - Serviço Social da Indústria, em Brasília. Ao longo dos anos, identificou-se um número significativo de projetos de inovação que direta ou indiretamente possuíam impactos reais de sustentabilidade. Apesar desta constatação, não existem diretrizes ou sistemáticas que maximizem tais impactos, gerando com isso, a necessidade de um estudo que permita identificar pontos de melhoria para o edital em questão e para as empresas que participam.

Este trabalho procurará responder a seguinte questão: Os projetos de inovação tecnológica desenvolvidos por empresas industriais brasileiras possuem no seu escopo resultados com impactos sociais e ambientais além dos econômicos? Espera-se levantar informações que permitam verificar se os conceitos de sustentabilidade estão sendo incorporados às práticas das empresas, dentro das suas ações inovadoras.

Assim, o objetivo geral deste trabalho é identificar impactos de sustentabilidade presentes nos projetos de inovação tecnológica desenvolvidos por empresas industriais brasileiras. Como objetivos específicos, temos:

- $\quad$ Realizar uma revisão teórica referente ao Edital SENAI SESI de Inovação, incluindo seus os resultados obtidos junto às indústrias brasileiras;

- $\quad$ Identificar o perfil das empresas que buscam apoio externo para projetos de inovação tecnológica;

- $\quad$ Analisar os projetos de inovação tecnológica aprovados no âmbito do Edital SENAI SESI de Inovação 2010 visando identificar a convergência das dimensões ambiental, econômica e social;

Neste artigo, são exploradas questões ligadas à sustentabilidade em processos projetos de indústrias brasileiras para identificar estratégias corporativas que permitam que empresas atinjam 
elevados níveis de competitividade, extrapolando sua busca por metas exclusivamente econômicas.

Inicialmente, são abordados conceitos de sustentabilidade no âmbito empresarial, ressaltando sua importância para as empresas, a sociedade e o meio ambiente. Em seguida, é feita uma análise do ambiente empresarial, que é caracterizado por um mercado globalizado e extremamente concorrido, onde as empresas precisam identificar formas para destacarem-se perante seus concorrentes. Para isso, buscam continuamente surpreender seus clientes por meio de produtos inovadores ou adotar baixos custos operacionais mediantes inovações de processos que proporcionem diminuição dos custos operacionais ou melhoria da qualidade de produtos. Por fim, é feita uma análise do Edital SENAI SESI de inovação, programa que existe desde 2004, responsável pela contratação de projetos que envolvem recursos financeiros e econômicos necessários ao desenvolvimento de projetos de inovação tecnológica junta a indústrias brasileiras.

\section{Desenvolvimento}

\subsection{Sustentabilidade}

A expressão "desenvolvimento sustentável", que começou a se tornar popular a partir da Conferência das Nações Unidas para o Meio Ambiente e Desenvolvimento (CNUMAD), realizada no Rio de Janeiro em 1992, tem na realidade uma longa trajetória. As sociedades industriais ensejavam, desde o seu início, reações críticas pelas destruições que causavam, seja por autores dissidentes, sejam por movimentos sociais, que chegam até os nossos dias e carregam consigo um rico passado de crítica civilizatória, embora tenham permanecido marginais até poucas décadas atrás em relação às correntes centradas no produtivismo.

Contrariamente ao ocorrido no movimento da qualidade, a adesão das empresas ao desenvolvimento sustentável vem inicialmente de fora para dentro, como um meio de se contrapor às críticas e objeções ao papel das empresas feitas por incontáveis entidades governamentais e da sociedade civil organizada, responsabilizando-as pelos processos de degradação social e ambiental que atingiam todo o planeta. Só recentemente a adesão das empresas passou a ser induzida por fatores de natureza empresarial ou, dito de outra forma, fazer parte desse movimento passou a ser um fator de competitividade, seja como fonte de diferenciação, seja como fonte de qualificação para continuar no mercado. A rapidez com que esse movimento foi aceito por amplos setores do empresariado, pelo menos no nível do discurso, não tem precedentes na história recente das empresas.

Coral (2002) destaca em seu trabalho as principais diferenças entre a empresa voltada à competitividade em seu sentido tradicional (econômico), e a empresa voltada à sustentabilidade. A princípio, a empresa que foca a competitividade busca a criação de valor aos acionistas, enquanto 
que a empresa ficada na sustentabilidade almeja a criação de valor aos grupos de interesse. $\mathrm{O}$ Quadro 1demonstra as principais diferenças entre estes dois enfoques:

Quadro 1 - Resumo comparativo entre competitividade e sustentabilidade

\begin{tabular}{|l|l|}
\hline Competitividade & Sustentabilidade \\
\hline Baseada em fatores econômicos e operacionais & $\begin{array}{l}\text { Baseada em fatores econômicos, sociais e } \\
\text { ecológicos }\end{array}$ \\
\hline $\begin{array}{l}\text { Visão de mundo restrita - empresa contra as } \\
\text { forças competitivas }\end{array}$ & $\begin{array}{l}\text { Visão de mundo mais ampla - parcerias para } \\
\text { obter vantagens competitivas }\end{array}$ \\
\hline $\begin{array}{l}\text { Legislação ambiental = aumento dos custos de } \\
\text { produção }\end{array}$ & Legislação ambiental = promoção da inovação \\
\hline Uso de tecnologias de produção tradicionais & Uso de tecnologias limpas de produção \\
\hline $\begin{array}{l}\text { Questões do meio ambiente natural geralmente } \\
\text { são vistas como ameaças }\end{array}$ & $\begin{array}{l}\text { Questões do meio ambiente natural geralmente } \\
\text { são vistas como novas oportunidades }\end{array}$ \\
\hline $\begin{array}{l}\text { Foco na redução de custos e eficiência } \\
\text { operacional }\end{array}$ & Foco na inovação \\
\hline Individualista & Cooperação \\
\hline
\end{tabular}

Fonte: Coral (2002)

Segundo Sachs (2002), o uso produtivo não necessariamente precisa prejudicar o meio ambiente ou destruir a diversidade, se tivermos consciência de que nossas atividades econômicas estão solidamente fincadas no ambiente natural.

Organização sustentável é a que simultaneamente procura ser eficiente em termos econômicos, respeitar a capacidade de suporte do meio ambiente e ser instrumento de justiça social, promovendo a inclusão social, a proteção às minorias e grupos vulneráveis, o equilíbrio entre os gêneros etc. (BARBIERI, 2007). Os dois conceitos de organização podem entrar em contradição, pois inovar em bases sistemáticas pode se tornar sinônimo de degradação sistemática do meio ambiente e da vida social.

Assim, uma organização inovadora sustentável "não é a que introduz novidades de qualquer tipo, mas novidades que atendam as múltiplas dimensões da sustentabilidade em bases sistemáticas e colham resultados positivos para ela, para a sociedade e o meio ambiente" (BARBIERI, 2007).

Não basta, para as empresas, apenas inovar constantemente, mas inovar considerando as três dimensões da sustentabilidade, a saber:

- Dimensão social - preocupação com os impactos sociais das inovações nas comunidades humanas dentro e fora da organização (desemprego; exclusão social; pobreza; diversidade organizacional etc.);

- Dimensão ambiental - preocupação com os impactos ambientais pelo uso de recursos naturais e pelas emissões de poluentes;

- Dimensão econômica - preocupação com a eficiência econômica, sem a qual elas não se perpetuariam.

O atendimento a essas dimensões torna o processo de inovação mais sofisticado e exigente, o que requer da organização um maior esforço para atender tecnicamente esse requisito. A inclusão 
das dimensões sociais e ambientais requer novos instrumentos e modelos de gestão, que só recentemente começaram a ser desenvolvidos com mais intensidade. Isso não é tarefa só das empresas que pretendem inovar. As instituições de ensino e pesquisa, os órgãos governamentais, as instituições de normalização e as organizações da sociedade civil também têm um papel relevante nessa questão.

\subsection{Inovação}

No início do século XX a relevância da inovação tecnológica havia sido destacada por Schumpeter (1912) definindo-a como a força central do dinamismo do sistema capitalista. Posteriormente diversos autores têm apresentado trabalhos teóricos e empíricos, os quais evidenciam a relação existente entre inovação tecnológica e desempenho comercial.

Para Schumpeter (1912), o conceito de inovação abrange cinco fatores: i) a introdução de um novo produto, que pode ser novo para os consumidores ou corresponder a uma nova qualidade de um produto já existente; ii) Desenvolvimento de um novo método de produção, que ainda não foi testado pelo setor em que a empresa está inserida, não sendo necessariamente uma descoberta científica; iii) abertura de um novo mercado, em que outras empresas do mesmo setor ainda não tenham entrado, podendo tal mercado ter existido antes ou não; iv) conquista de uma nova fonte de insumos, novamente podendo essa fonte já existir ou ter sido criada; v) estabelecimento de uma organização industrial, seja pela criação de um monopólio, ou pela fragmentação de um monopólio.

A inovação é importante porque amplia os recursos comandados pelas empresas no processo de competição. A inovação e a diferenciação de produto têm impacto positivo sobre a geração de emprego, renda, desempenho e crescimento das empresas (DE NEGRI, 2005).

De acordo com Daft (2008), novos produtos e serviços são um caso especial de inovação porque são usados por clientes de fora da organização. Uma vez que os novos produtos ou serviços são projetados para serem vendidos no ambiente, a incerteza sobre a adequação e o sucesso de uma inovação é muito grande.

O conceito de inovação tecnológica que será utilizado no presente artigo é aquele definido e utilizado pelo Manual de Oslo (2004), que é mais restrito do que o utilizado por Schumpeter (1912). Segundo a OCDE, Inovações Tecnológicas em Produtos e Processos (TPP - Technological Product and Process), compreendem as implantações de produtos e processos tecnologicamente novos e substanciais melhorias tecnológicas em produtos e processos.

Uma inovação TPP envolve uma série de atividades científicas, tecnológicas, organizacionais, financeiras e comerciais. Uma empresa inovadora em TPP é uma empresa que tenha implantado produtos ou processos tecnologicamente novos ou com substancial melhoria tecnológica durante o período em análise. 
O termo produto tecnologicamente aprimorado é um produto existente, cujo desempenho tenha sido significativamente aprimorado ou elevado, por exemplo, por meio do uso de componentes ou materiais de desempenho melhor, ou um produto complexo que consista em vários subsistemas técnicos integrados pode ser aprimorado por meio de modificações parciais de um dos subsistemas (OCDE, 2004).

A inovação tecnológica em processos produtivos é a adoção de processos novos ou significativamente melhorados. Isoladamente a inovação tecnológica não consegue propiciar mudanças radicais no sistema econômico vigente; é necessário que essa inovação tecnológica chegue até o mercado, e para isso, o processo de difusão possui um papel importante no processo de inovação. Segundo Manual de Oslo, a difusão tecnológica é a maneira como as inovações se espalham mediante os canais de mercado ou a partir de sua primeira implantação mundial para outros países e regiões. Sem a difusão, a inovação não terá impacto no sistema econômico.

\subsection{Competitividade}

O objetivo de qualquer empresa com fins lucrativos é obter o maior retorno possível sobre o capital investido. Para isto, utiliza-se de todas as ferramentas disponíveis para estar à frente de seus concorrentes, obterem maiores margens e fatias de mercado. Em outras palavras, a empresa deve ser competitiva.

Segundo Porter (1992), a empresa deve conhecer as forças que atuam sobre a sua competitividade, como a ameaça de entrada de novas empresas, produtos substitutos, a rivalidade da concorrência e o poder de negociação da empresa com fornecedores e clientes. Com a análise destas cinco variáveis a empresa desenvolve estratégias que a destacam no mercado, diferenciando-se dos demais.

A competitividade, encarada como a forma de as organizações sustentarem suas posições mercadológicas Coutinho; Ferraz (1995) trazem em seu bojo a necessidade de criação e renovação de vantagens competitivas.

As exigências requeridas no atual cenário de competição elevada têm corroborado para uma redefinição nas formas de gestão das empresas, sobretudo, as de pequeno e médio porte, adequando-se aos novos contextos organizacionais, a fim de melhor competirem com os seus concorrentes (BARROS, 2010).

A abertura comercial vivida pelo país a partir da década de 90 encontrou uma indústria acomodada, que teve dificuldades para inserir-se internacionalmente, pois não foi constituída para tal. Os grupos brasileiros ficaram relativamente menores diante de seus congêneres internacionais. A reação da indústria foi a de racionalizar processos produtivos para o aumento da eficiência fabril (MEIRELLES, 2008). A estratégia adotada era coerente com a estrutura industrial calcada na 
transformação física, mas apenas tendia a reforçar a função manufatura, não sendo, por si só, suficiente para garantir a competitividade necessária para sua sobrevivência.

A sustentação de uma vantagem competitiva vai depender da capacidade da empresa em inovar constantemente, combinando suas competências essenciais de forma que não possa ser imitada no curto prazo por seus concorrentes. O investimento em Pesquisa e Desenvolvimento é muito importante para que a inovação tecnológica garanta diferenciação à empresa.

Investimento em pesquisa e desenvolvimento (P\&D), concepção e projeto de novos produtos, investimento em logística, fortalecimento de marcas, dentre outras, passam a ser mais relevantes na competitividade das empresas.

As inovações científicas, que ampliam o conhecimento relevante em nível mundial, na verdade, estão longe de qualquer inovação que agregue valor a produtos e os torne mais competitivos (NICOLSKY, 2002). Considerando este novo contexto, podemos entender inovação tecnológica como um processo realizado por uma empresa para introduzir ou modificar produtos através da incorporação de novas soluções técnicas, funcionais ou estéticas.

Entretanto, as mudanças no ambiente global que ocorreram nos últimos anos trouxeram consigo outras variáveis que começam a fazer parte da responsabilidade das empresas - e conseqüentemente de sua estratégia para a competitividade. Os stakeholders transformam-se em indivíduos ou grupos que tem interesses materiais ou imateriais na empresa - pressionam para uma atuação empresarial ecologicamente correta e socialmente justa, de forma que não basta mais à empresa tão somente o êxito econômico.

A observação mais detalhada destas diferenças permite verificar que o conceito de sustentabilidade não é antagônico ao de competitividade, mas sim, engloba este último, possuindo uma visão de mundo mais ampla em que os fatores sociais e ambientais são adicionados aos aspectos econômicos. Para que seja sustentável, a empresa deve ser competitiva no mercado em que está inserida para que esta estabilidade econômica permita investimentos nas áreas ambientais e sociais.

\section{Edital SENAI SESI de inovação}

A partir de 2004, o SENAI lança anualmente um Edital voltado para empresas do setor industrial, com objetivo de promover projetos de pesquisa aplicada com ênfase em inovação tecnológica. O programa disponibiliza apoio financeiro associado ao suporte técnico através de sua infra-estrutura laboratorial e de recursos humanos.

Em 2008, foi estabelecida uma parceria com o Ministério da Ciência e Tecnologia e Conselho Nacional de Desenvolvimento Científico e Tecnológico (CNPq) que permitiu a incorporação de bolsas de Desenvolvimento Tecnológico e Industrial - DTI para complementar as 
equipes dos projetos com profissionais com formação acadêmica para a realização das pesquisas nos Centros de Tecnologia do SENAI.

A partir de 2009, o edital passou a contar também com a parceria do SESI, passando-se a chamar Edital SENAI SESI de Inovação, incorporando ao seu escopo e objetivo a promoção de projetos de inovação social com forte apelo à melhoria da qualidade de vida do trabalhador da indústria e responsabilidade social. Segue abaixo a evolução do número de projetos apoiados pelo edital:

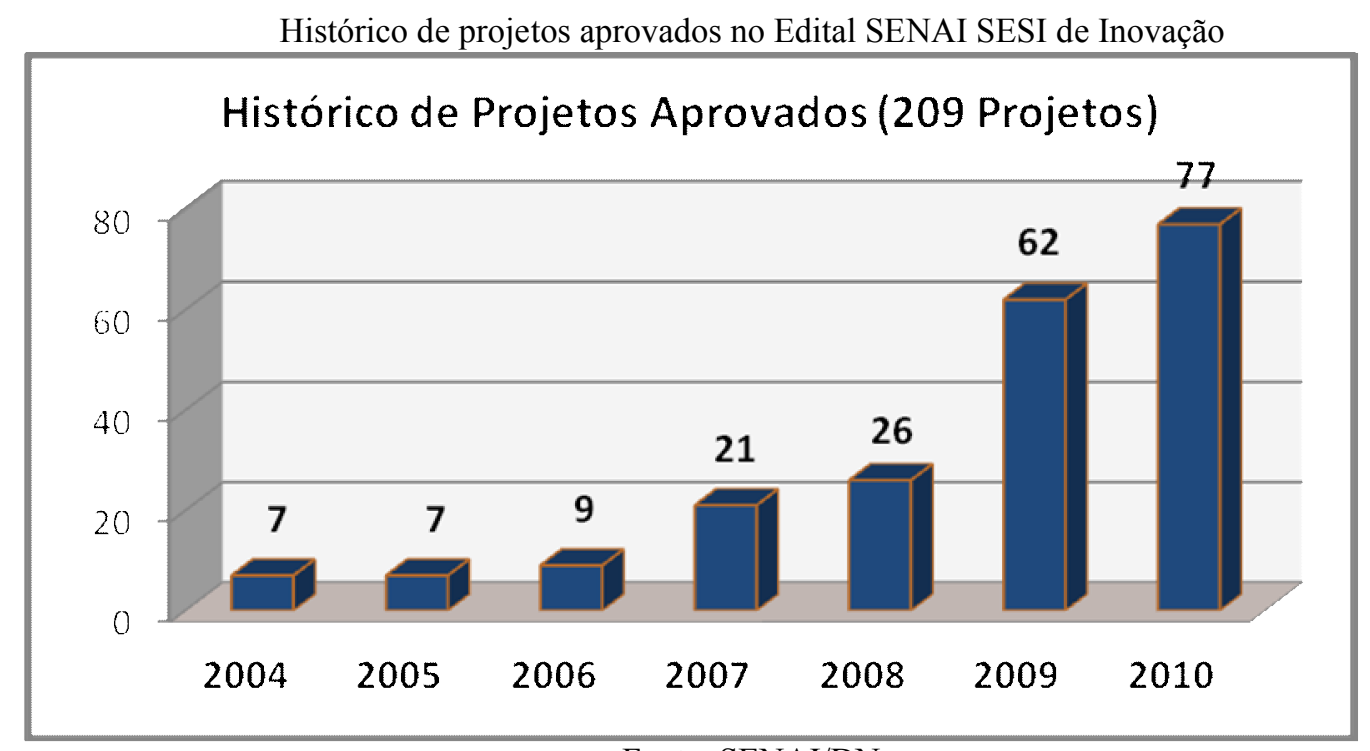

Fonte: SENAI/DN

Para garantir o atendimento da crescente demanda por projetos de inovação, houve a necessidade de um aumento significativo do aporte de recursos financeiros e econômicos das instituições envolvidas. A figura abaixo apresenta a evolução dos recursos do edital, dividida por instituição:

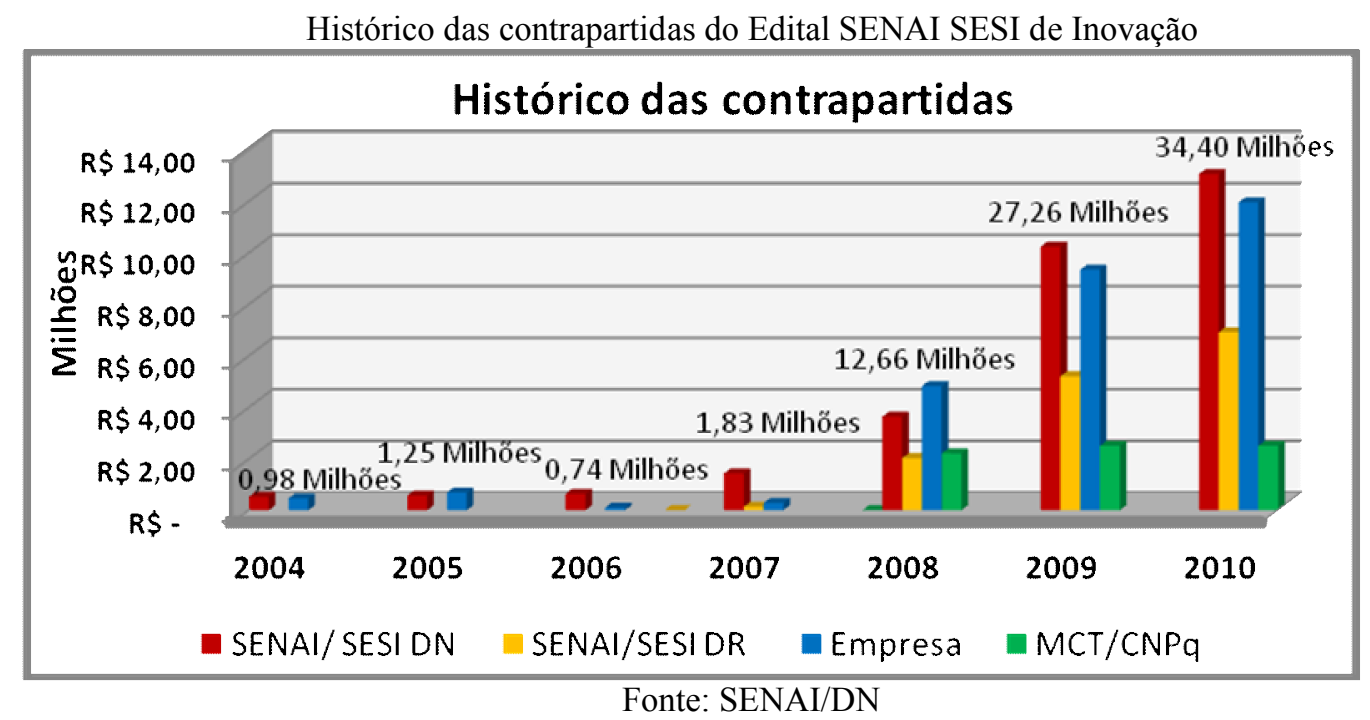


Os projetos apoiados pelo edital exigem a participação de empresas do setor industrial, que por meio de apoio técnico e financeiro, encontram condições para desenvolverem seus projetos de inovação tecnológica e social. O gráfico abaixo apresenta um resumo de como funcionam as parcerias necessárias para o desenvolvimento de um projeto:

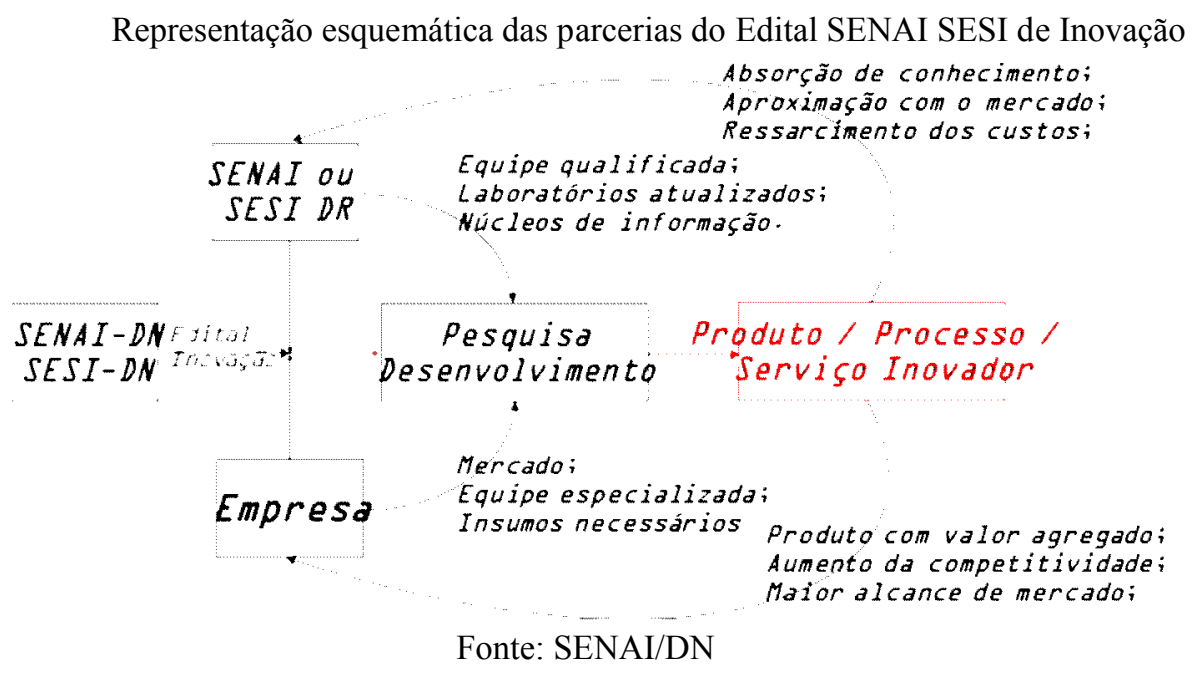

De acordo com o gráfico, a parceria entre o SENAI, SESI e a empresa industrial permite a sinergia necessária à pesquisa aplicada, motivada por uma demanda real identificada. Dessa forma. os projetos de inovação tecnológica desenvolvimento com o apoio técnico do SENAI e do SESI têm seus riscos menores por possuírem as condições necessárias para a o desenvolvimento de novos produtos, processos ou serviços alinhados com as necessidades do mercado.

O principal benefício para a empresa é o aumento de sua competitividade em mercado cada vez mais concorrido e a experiência em realizar pesquisa aplicada e desenvolvimento tecnológico, ações necessárias para continuar inovando de forma sistemática e sustentável.

Enquanto isso, o SENAI e o SESI, à medida em que assistem as empresas nos projetos de inovação tecnológica, passam a cumprir seu papel junto às indústrias brasileiras, além de criar competências internas e infra-estrutura laboratorial para a promoção da inovação.

O Serviço Nacional de Aprendizagem Industrial (SENAI) é uma instituição privada brasileira de interesse público, sem fins lucrativos cuja missão é contribuir para a elevação da competitividade da indústria brasileira através da prestação de serviços tecnológico (assessoria, pesquisa aplicada, design, serviço laboratorial, informação tecnológica) e educação profissional nos níveis básicos (aprendizagem, qualificação, aperfeiçoamento), médio (técnico) e Ensino superior (superior tecnológico, pós-graduação).

O Serviço Social da Indústria (SESI) é uma instituição privada brasileira, sem fins lucrativos cuja finalidade é promover o bem-estar social, o desenvolvimento cultural e a melhoria da 
qualidade de vida do trabalhador que atua nas indústrias, de sua família e da comunidade na qual estão inseridos, em geral.

O edital possui um escopo único e estabelece um conjunto de critérios de avaliação comuns, mas considera uma divisão dos projetos de acordo com tipo de produto esperado. Os projetos podem ser: SENAI, SESI ou SENAI/SESI. Estes últimos são desenvolvidos por profissionais das duas entidades, reunindo produtos que apresentam mais facilmente impactos de sustentabilidade.

As propostas de projetos recebidas pela comissão organizadora do edital são avaliadas de acordo com o descrito abaixo:

- $\quad$ Avaliação premilinar - compreende análise objetiva do atendimento aos elementos obrigatórios do edital;

- $\quad$ Avaliação quantitativa - pontuação objetiva dos critérios de avaliação associados às contrapartidas das empresas, realizada matematicamente pelo sistema de gestão do edital;

- $\quad$ Avaliação qualitativa - pontuação objetiva dos critérios de avaliação associados às informações qualitativa dos projetos, realizada pelos avaliadores;

- $\quad$ Listagem dos projetos aprovados, considerando os mais bem pontuados, limitados pelo orçamento disponível.

O edital estabelece alguns elementos obrigatórios, que podem ser considerados requisitos mínimos exigidos que possuem caráter eliminatório. A seguir, estão listadas as principais exigências do edital em 2010:

- Empresa industrial parceira no projeto, estabelecida há pelo menos 01 (um) ano, contado até a data limite da submissão da proposta, comprovado mediante apresentação da sua inscrição estadual;

- Contrapartidas pela empresa e pelo SENAI/SESI Regional envolvendo recursos financeiros;

- $\quad$ Participação de especialista da empresa e do SENAI/SESI Regional no projeto como contrapartida;

- $\quad$ Relatório de pesquisa de anterioridade para produtos e processos;

- Considerar um produto, processo ou serviço inovador como resultado final;

- $\quad$ Acordo de cooperação técnica entre SENAI/SESI e empresa.

Tabela 1 - Critérios de avaliação utilizados no edital SENAI SESI de inovação 2010

\begin{tabular}{|c|c|}
\hline 1 & CARÁTER INOVADOR DO PROJETO \\
\hline 1.1 & Grau de inovação do projeto \\
\hline
\end{tabular}




\begin{tabular}{|c|l|}
\hline 1.1 & Qualidade de relatório de anterioridade apresentado \\
\hline $\mathbf{2}$ & \multicolumn{1}{c|}{ ANÁLISE DE VIABILIDADE DO PROJETO } \\
\hline 2.1 & Estudo de mercado / Caracterização da demanda \\
\hline 2.2 & Estratégias de marketing / Potencial de replicabilidade \\
\hline 2.3 & Potencial de impacto na produtividade da empresa \\
\hline 2.4 & Impactos indiretos (ambiental e social) \\
\hline 3 & DESCRIÇÃO DO PROJETO \\
\hline 3.1 & Título condizente com o objetivo do projeto \\
\hline 3.2 & Objetivo do projeto \\
\hline 3.3 & Análise SWOT (forças, fraquezas, oportunidades, ameaças) \\
\hline 3.4 & Descrição do escopo \\
\hline 3.5 & Métodos utilizados para condução do projeto \\
\hline 3.6 & Cronograma com etapas, tarefas e marcos de entrega definidos \\
\hline 3.7 & Recursos humanos, financeiros e econômicos adequados ao desenvolvimento do projeto \\
\hline 3.8 & Planejamento da avaliação final, incluindo medição de alcance do objetivo do projeto \\
\hline $\mathbf{4}$ & PARTICIPAÇÃO DA EMPRESA PARCEIRA NO PROJETO \\
\hline 4.1 & Recursos financeiros e/ou de matéria-prima disponibilizados pela empresa \\
\hline 4.2 & Recursos econômicos disponibilizados pela empresa \\
\hline $\mathbf{5}$ & \\
\hline 5.1 & Recursos financeiros e de matéria-prima disponibilizados \\
\hline 5.2 & Recursos econômicos disponibilizados \\
\hline 5.3 & Histórico do SENAI Regional no Edital SENAI SESI de Inovação \\
\hline
\end{tabular}

Fonte: Edital SENAI SESI de inovação 2010

Segundo a Organização para a Cooperação Econômica e Desenvolvimento - OCDE, uma inovação TPP é considerada implantada se tiver sido introduzida no mercado (inovação de produto) ou usada no processo de produção (inovação de processo).

Os projetos apoiados pelo edital são conduzidos de forma que seus resultados sejam efetivamente inseridos no mercado, onde são monitorados a partir do indicador de desempenho “Taxa de Incorporação no Mercado", cujo métrica considera a relação: Projetos inseridos no mercado / Total de projetos concluídos.

Representação do indicador de desempenho extraído no $1^{\circ}$ trimestre de 2010

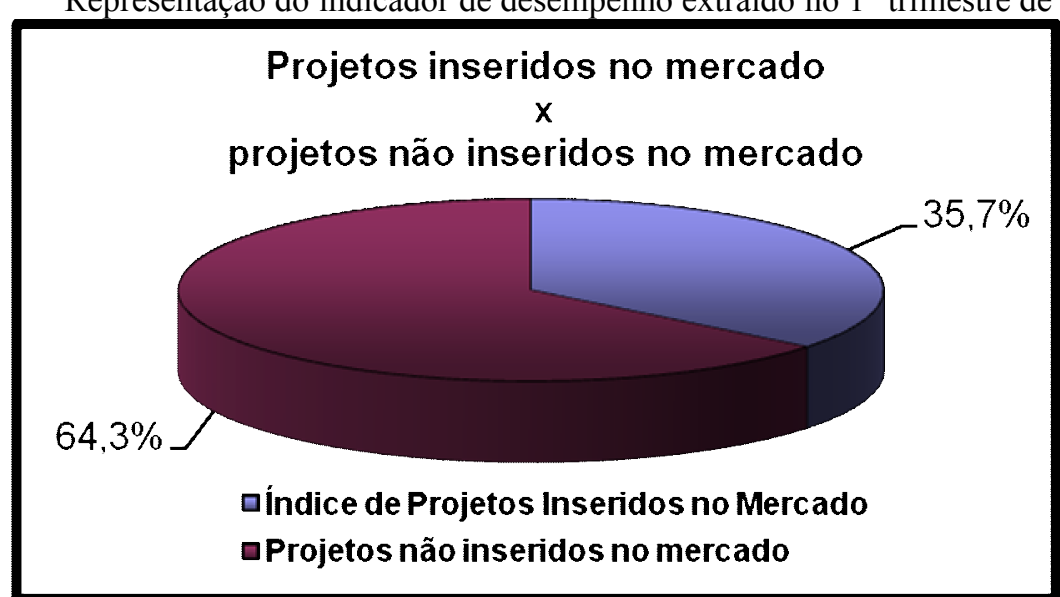

Fonte: UFRJ / PROTEC 
Para a escolha do indicador foi considerada sua relação direta com benefícios esperados pelas instituições promotoras do edital para as empresas e sociedade, de uma forma geral. Entre tais benefícios, podemos destacar:

-Gerar e substituir tecnologias de outros países;

- Aumentar investimentos e criar competências nacionais para realização de $\mathrm{P} \& \mathrm{D}$;

-Melhorar a qualidade dos produtos brasileiros;

- Aumentar a produtividade de processos de fabricação;

-Criar mais e melhores empregos;

-Disseminar práticas de responsabilidade social;

-Diminuir impactos ambientais.

Daft (2008) apresenta as razões para o sucesso de um novo produto a partir de conclusões de uma pesquisa realizada com 200 projetos de 19 laboratórios de química, farmácia, eletrônicos e de petróleo para conhecer os índices de sucesso. Para ser considerado bem sucedido, o projeto passa por três estágios de desenvolvimento: solução técnica, comercialização e sucesso de mercado. Desses três estágios, pôde-se verificar na pesquisa que:

- $\quad$ Na média, $57 \%$ de todos os projetos atingiram seus objetivos técnicos;

- De todos os projetos que foram iniciados, menos de 1/3 (31\%) completaram a fase de distribuição e comercialiação. Vários projetos falharam nesse estágio por causa dos resultados desfavoráveis da estimativa de produção e demandas de mercado;

- $\quad$ Somente $12 \%$ de todos os projetos originalmente desenvolvidos alcançaram sucesso econômico. A maior parte dos produtos comercializados não obteve retorno suficiente para cobrir o custo de desenvolvimento e produção. Isso significa que somente cerca de um projeto em oito reverte em lucro para a companhia.

Estudo posteriores indicaram que o sucesso de uma inovação está relacionadao a colaboração entre os departamentos técnicos e de marketing. Novos produtos e serviços bemsucedidos parecem ser tecnicamente sólidos e também cuidadosamente talhados para as necessidades dos clientes.

Portanto, há um padrão distinto de adaptar as inovações às necessidades do cliente, fazer uso eficiente da tecnologia, e ter o apoio de altos executivos influentes. Essas idéias tomadas em conjunto indicam que um projeto, para obter sucesso, deve contar com uma coordenação horizontal de diferentes departamentos de uma empresa.

\section{Procedimentos Metodológicos}


A pesquisa realizada pode ser caracterizada como exploratória e conduzida sob a forma de estudo de caso, a qual procurou compreender o modelo de inovação tecnológica utilizado e sua relação com as três dimensões da sustentabilidade: econômica, ambiental e social. YIN afirma que o estudo de caso é uma inquirição empírica que investiga um fenômeno contemporâneo dentro de um contexto da vida real, quando a fronteira entre o fenômeno e o contexto não é claramente evidente e onde múltiplas fontes de evidência são utilizadas. O método, muitas vezes, é colocado como sendo mais adequado para pesquisas exploratórias e particularmente útil para a geração de hipóteses (YIN, 1989).

A análise dos dados foi embasada na inferência obtida a partir da triangulação dos dados existentes, a qual se refere à correlação entre diferentes fontes de dados (referencias bibliográficas, documentos e observação não participante).

Foi utilizada a base de dados do edital, disponível por meio do sistema de gestão dos projetos de inovação tecnológica.

Num primeiro momento, foi produzida uma análise quantitativa dos dados das propostas, sendo considerados: localização geográfica, porte das empresas parceiras, área tecnológica, setor industrial, tipo de inovação, contrapartidas, entre outras informações.

Em seguida, foi feita uma análise qualitativa de conteúdo, considerando principalmente as propostas dos projetos submetidos ao edital, sendo levantadas categorias emergentes de análise, conforme apontado pela técnica de Bardin (2004).

As propostas contêm, entre outras, as seguintes informações: objetivo, metodologia, estudo de mercado, análise de viabilidade técnica e econômica, descrição do escopo do produto/processo/serviço, impactos.

Motivado pela perspectiva de que os projetos foram avaliados e aprovados considerando critérios que estabelecem requisitos técnicos abrangentes, o estudo está centrado no estabelecimento das conexões conceituais entre as definições de inovação e sustentabilidade e sua relação com as inovações tecnológicas em produtos, processos ou serviços desenvolvidos pelas empresas industriais brasileiras.

Foram utilizadas ferramentas de filtro e busca eletrônica da base de dados e internet como meio de pesquisa das informações.

Com relação à composição da amostra, foram analisados 77 projetos aprovados no Edital SENAI SESI de Inovação 2010. A escolha das propostas justifica-se pela representatividade das empresas, conforme descrito abaixo:

- $\quad$ atenderam todos os elementos obrigatórios do edital;

- $\quad$ envolvimento de onze estados brasileiros;

- $\quad$ participação de micro, pequenas, médias e grandes empresas; 
- $\quad$ doze áreas tecnológicas.

O levantamento dos dados atende aos termos de confidencialidade estabelecidos pelo Edital, não havendo qualquer identificação ou divulgação de informações sobre as empresas ou tecnologias descritas nos projetos.

Diante de tais considerações acerca do percurso metodológico utilizado para realização deste artigo, serão enfatizados no tópico seguinte a análise e interpretação dos resultados obtidos no estudo.

\section{Análise e interpretação dos resultados}

Com base nos dados obtidos, passa-se agora à análise das informações referentes ao perfil das empresas que aprovaram projetos e, em seguida, à análise dos projetos em si. A estratificação das informações priorizou identificar o grau de sustentabilidade dos impactos previstos nos projetos.

Inicialmente, a figura abaixo apresenta a distribuição dos projetos aprovados em 2010, por estado:

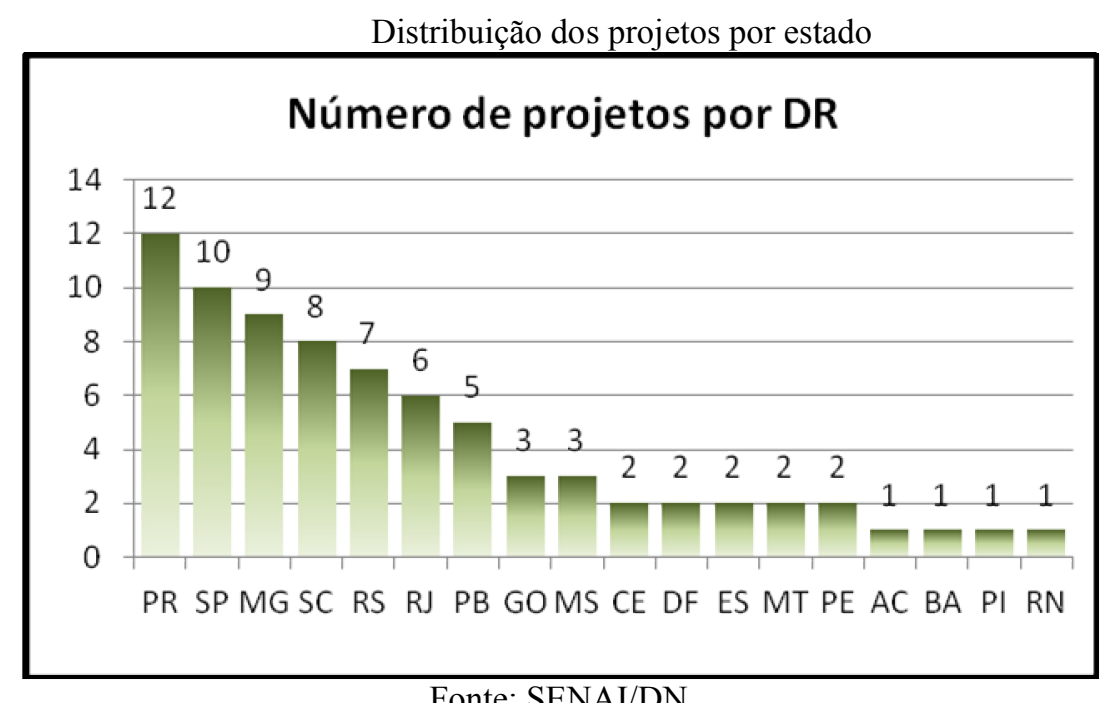

Fonte: SENAI/DN

Pode-se perceber uma grande concentração dos projetos nas regiões sul e sudeste, o que permite concluir que existe uma relação entre o número de projetos com as regiões que possuem um maior número de indústrias. Outro fator que influencia a distribuição geográfica dos projetos é a estratégia adotada pelo SENAI ou SESI local para divulgar o edital e mobilizar suas equipes para elaborar os projetos conjuntamente.

Para caracterizar o perfil das empresas que possuem projetos aprovados, foi feita uma análise pelo porte, considerando o número de funcionários. Essa informação é importante para 
adequar estratégias do edital para as edições futuras a partir da definição do público alvo. A seguir são apresentadas as empresas, divididas pelo porte:

Distribuição pelo porte das empresas

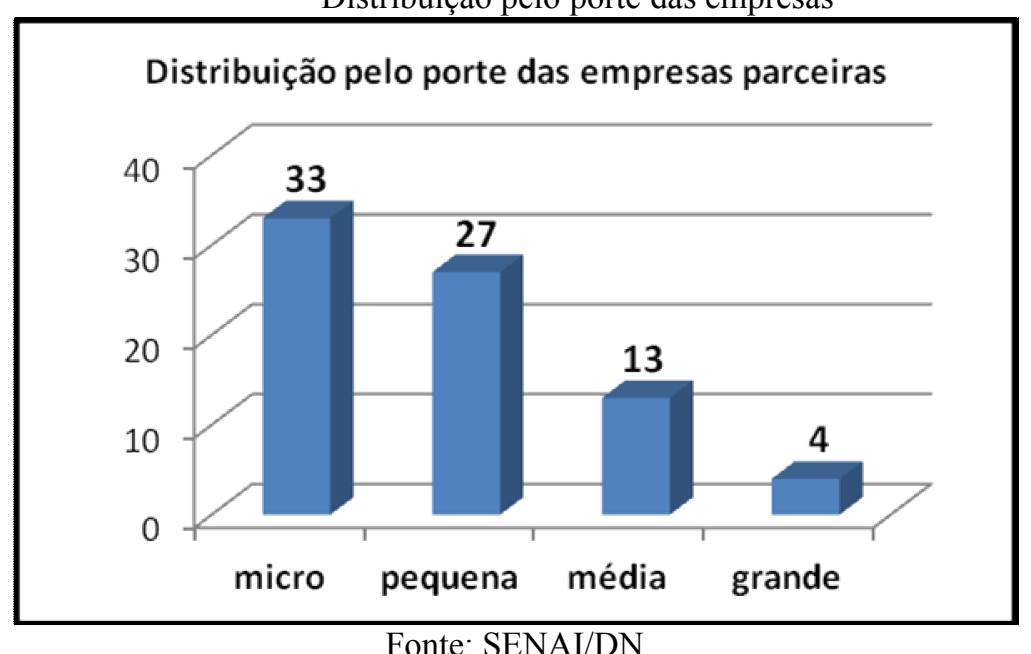

Com base nos resultados encontrados, pode-se verificar que micro e pequenas empresas compõem $77 \%$ dos projetos aprovados. O interesse em captar recursos financeiros e receber apoio técnico para inovar pode ser o grande motivo que leva essas empresas a buscarem o edital.

Os projetos apresentados pelas grandes empresas apresentam, na sua maioria, novas metodologias voltadas à melhorar as condições de trabalho de funcionários. Pode-se perceber ainda projetos dessas empresas que buscam otimizar processos industriais, onde indiretamente, ocorre uma redução do consumo de insumos e/ou matéria-prima.

O próximo gráfico apresenta a distribuição por setor industrial das empresas parceira que conseguiram aprovar seus projetos.

Desempenho das propostas por setor industrial

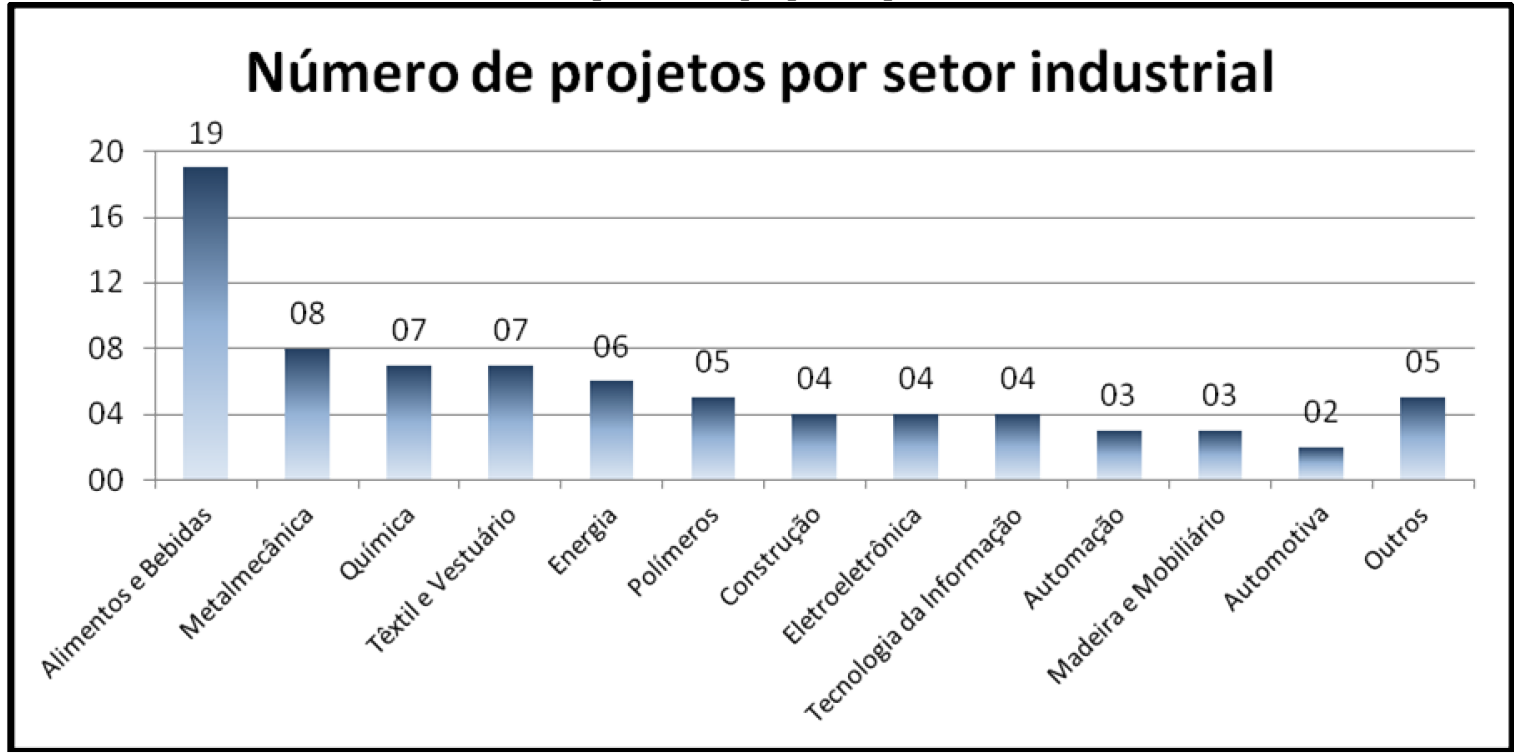

Fonte: SENAI/DN 
Pode-se perceber uma predominância de projetos do setor industrial “Alimentos e bebidas”, onde destacam-se os projetos que buscam desenvolver alimentos funcionais e orgânicos. Uma parcela significativa destes projetos envolve o melhor aproveitamento de insumos para a produção desses alimentos, diminuindo significativamente desperdícios.

Considerando principalmente os objetivos gerais, estudo de mercado, análise da viabilidade técnica e econômica e descrição dos produtos dos projetos analisados, procurou-se identificar a convergência entre as dimensões da sustentabilidade. Para isso, foram considerados sustentáveis os projetos que apresentaram: tecnologias que proporcionam melhoria da qualidade de vida no trabalho, desenvolvimento de produtos orgânicos ou funcionais, tecnologias voltadas à reciclagem, tratamento de efluentes industriais ou utilização de energia alternativa. A figura abaixo apresenta os projetos divididos quanto a existência de impactos de sustentabilidade:

Avaliação dos projetos sustentáveis

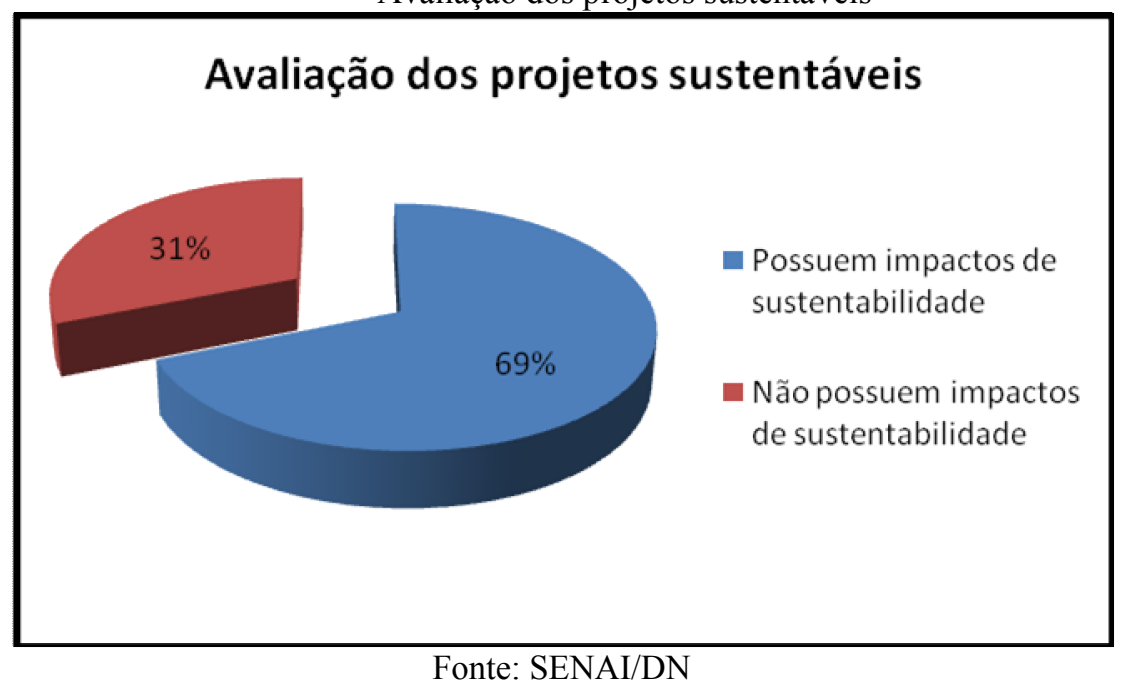

Com relação aos projetos que não apresentaram evidências objetivas quanto aos seus impactos de sustentabilidade, foi verificado que:

- $\quad 42 \%$ dos projetos possuem no seu escopo o desenvolvimento de novas máquinas, componentes, equipamentos e/ou embalagens;

- $\quad 58 \%$ dos projetos possuem no seu escopo tecnologias para otimizar processos produtivos.

Neste último caso, apesar de não haver evidências objetivas nos projetos sobre os impactos de sustentabilidade, pode-se concluir que seria possível apresentar benefícios associados à sustentabilidade, visto que a melhoria da eficiência de processos produtivos remete a diminuição do consumo de insumos em geral (energia, matéria-prima, espaço físico, etc). 
Um trabalho de sensibilização dos gestores de projetos com foco em aspectos relativos às questões de sustentabilidade, direcionados à fase de planejamento, proporcionaria uma melhora dos resultados obtidos.

Considerando um estudo mais detalhado dos projetos que possuem impactos de sustentabilidade relevantes apresentados na figura acima, foi realizada uma classificação que considerou os produtos dos projetos. O gráfico abaixo apresenta a distribuição dos projetos de acordo com o tipo de produto sustentável:

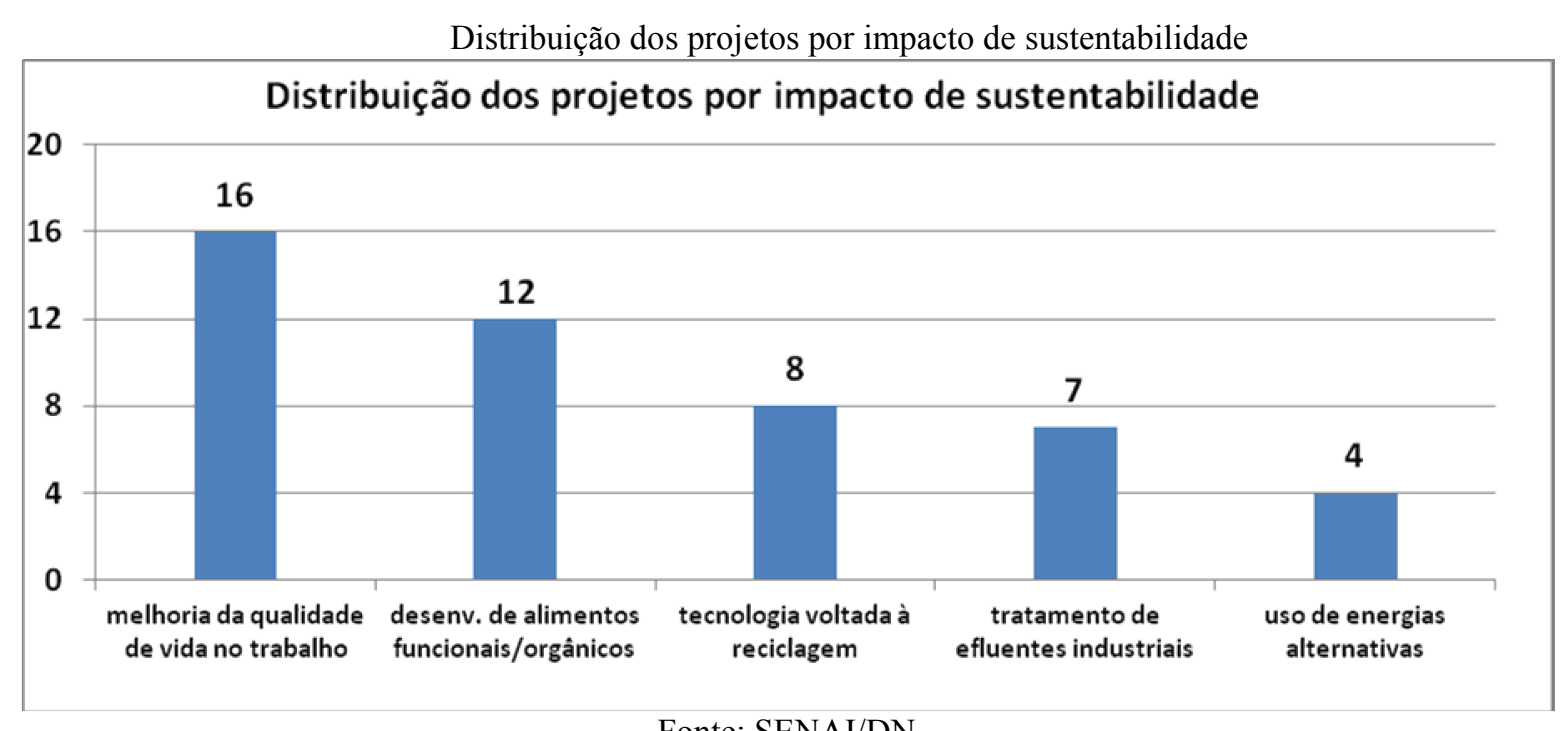

Fonte: SENAI/DN

De acordo com a figura, os projetos que proporcionam melhoria da qualidade de vida no trabalho destacam-se diante dos demais. Esse destaque deve-se ao direcionamento das exigências do edital a esse tipo de projeto pelo SESI, pois estão diretamente alinhados com a missão desta instituição. Isso não precisa, necessariamente, limitar o escopo de inovação social considerado no edital.

Com relação às demais categorias, pode-se verificar que grande parte dos projetos está alinhada com tendências de consumo e exigências da sociedade, sejam elas reguladoras ou tácitas. A partir de uma rápida análise, podemos concluir que:

- $\quad$ A busca pela qualidade de vida direciona as empresas a desenvolverem alimentos funcionais e orgânicos;

- A necessidade de diminuir o consumo de recursos naturais por questões ambientais direciona as empresas a desenvolverem tecnologias voltadas à reciclagem e à utilização de energias alternativas e;

- A necessidade de diminuir os impactos ambientais decorrentes da ação industrial direciona as empresas a buscarem a eficiência e o correto tratamento de efluentes e resíduos; 


\section{Considerações finais}

A partir da análise do edital SENAI SESI de inovação, verificamos pesos diferentes dos critérios de avaliação dos projetos desenvolvidos pelo SENAI, que prioriza a dimensão econômica. No caso de projetos SESI, a dimensão priorizada é a social, com destaque àqueles que proporcionam melhoria das condições de trabalho de funcionários das empresas parceiras.

Apesar do direcionamento dado pelo edital para projetos com forte apelo para as dimensões econômicas e sociais, visto que compõem a missão das entidades promotoras do edital, percebe-se que as questões ambientais são consideradas nos projetos, com impactos reais nos seus resultados. Tal constatação pode ser explicada pelas novas tendências de consumo de produtos e serviços ambientalmente corretos.

De forma geral, podemos afirmar que os projetos apoiados pelo edital contemplam as três dimensões de sustentabilidade: econômica, ambiental e social.

Como exemplo de projetos que aborda bem as três dimensões, podemos citar aqueles cujo interesse parte da busca por ganhos econômicos, onde sua execução prevê experimentos, normalmente em escala piloto, que permitem ajustar parâmetros para se obter diminuição do consumo de insumos (energia e matéria prima), melhoria da qualidade de efluentes e da qualidade dos produtos, adequação das condições de trabalho, entre outros ganhos econômicos, sociais e ambientais.

Diante desta constatação e visando aumentar os benefícios gerados pelos projetos, pode ser feito um trabalho de sensibilização das equipes do SENAI e do SESI para orientar os empresários para explorar de forma mais consistente as questões da sustentabilidade no processo de elaboração das propostas. Essa sensibilização pode ser estendida a todo o processo de divulgação do edital, realizado junto às empresas, institutos de ciência e tecnologia, sindicatos e associações industriais.

A figura 09 apresenta cinco categorias que, com exceção daquela que refere-se a qualidade de vida no trabalho, dependem de desenvolvimento de tecnologias específicas para atingir seus objetivos. De acordo com o resultado apresentado, pode-se perceber que a sustentabilidade já tem espaço na agenda da indústria brasileira, visto que $69 \%$ dos projetos apresentam a coexistência de impactos econômicos, sociais e ambientais. Pode-se associar essa realidade às novas exigências mercadológicas que buscam identificar nas atividades realizadas pelas empresas, compensações para os prejuízos ambientais gerados pela sua atuação.

As entidades promotoras do edital devem desenvolver programas de capacitação dos gestores de projetos de forma a melhorar a qualidade dos projetos e direcionar seu planejamento para abordar todas as dimensões da sustentabilidade. Desta forma, a contribuição para garantir a 
competitividade da indústria brasileira, principalmente no mercado internacional, será aumenta visto que vários mercados adotam como critérios de compra não só o preço, mas evidências de que a empresa fornecedora possui programas sociais e/ou ambientais.

Uma vez identificado os casos de sucesso, cuja competitividade da empresa tenha sido fortalecida, deve-se buscar a replicabilidade dos benefícios obtidos no projeto a outras empresas, despertando com isso, uma consciência sustentável. Um projeto replicável é caracterizado pela sua capacidade, após sua conclusão, de propagar a metodologia, a tecnologia ou o conhecimento gerado, beneficiando um número maior de pessoas ou empresas.

A consciência de que é possível trabalhar aspectos econômicos, sociais e ambientais conjuntamente, de forma a maximizar os negócios, é fundamental para identificar e disseminar as melhores práticas da gestão contemporânea nas empresas brasileiras.

\begin{abstract}
This paper examines technological innovation projects developed by Brazilian companies seeking external technical and financial support. We conducted a literature review to characterize the reality of technological innovation in Brazilian companies and the importance of sustainability to their business, considering the interests of all stakeholders. An exploratory survey was developed from information obtained from the 77 projects approved in the Announcement SENAI SESI Innovation 2010. Technological innovations in the projects considered in the sample chosen may involve the optimization of manufacturing processes, improvements in product design or development of new methodologies applied to the routine of social workers in industries that may be replicable in other companies. This paper proposes to raise general information, considering the innovative activities of businesses, environmental and social impacts of projects and check the end, if there are real impacts on the sustainability of these enterprises.
\end{abstract}

Key-words: sustainability; competitiveness; innovation; SENAI/SESI.

\title{
Referências
}

BARBIERI, J. C. Organizações inovadoras sustentáveis. São Paulo, Atlas, 2007.

BARDIN. Análise de Conteúdo. Lisboa: Edições 70, 3ª Ed. 2004.

BARROS, R. A. et al. Práticas de sustentabilidade empresarial no APL calçadista de Campina Grande/PB - um estudo de caso. Revista Gestão Industrial, 2010.

CAMPOS, C. A organização inconformista: como identificar e transformar mentes revolucionárias em um diferencial competitivo. São Paulo: Editora FGV. 2001

COUTINHO, L. G., \& FERRAZ, J. C. Estudo da competitividade da indústria brasileira. Campinas: Papirus. 1995

CORAL, E. Modelo de planejamento estratégico para a sustentabilidade empresarial. (Tese de Doutorado). Florianópolis: UFSC, 2002.

DAFT, R. L. Organizações: Teoria e projetos. tradução da $9^{a}$ edição americana. Editora Cengace Learning, 2008;

DE NEGRI, J. A; SALERNO, M. S. Inovações: padrões tecnológicos e desempenho das firmas industriais brasileiras, Brasília, IPEA, 2005. 
DRUCKER, P. F. As novas realidades: no governo e na política, na economia e nas empresas, na sociedade e na visão do mundo. São Paulo: Pioneira, 1991.

IBGE - Instituto Brasileiro de Geografia e Estatística. Pesquisa de inovação tecnológica - PINTEC, Rio de Janeiro, IBGE, 2009.

MEIRELLES, J.L. F. Inovação tecnológica na indústria brasileira: investimento, financiamento e incentivo governamental. São Carlos. 2008

NONAKA, I. A empresa criadora de conhecimento. In K. Starkey (Org.). Como as organizações aprendem: relatos do sucesso das grandes empresas. São Paulo: Futura, 1997.

NONAKA, I.; TAKEUCHI, H. Criação de conhecimento na empresa: como as empresas japonesas geram a dinâmica da inovação. Rio de Janeiro: Campus, 1997.

OCDE - Organização para a Cooperação Econômica e Desenvolvimento. Manual de Oslo: proposta de diretrizes para a coleta e interpretação de dados sobre inovação tecnológica. OCDE, 2004.

OLIVEIRA, A. F.; TAMAYO, A. Inventário de perfis de valores organizacionais. Revista de Administração de Empresas, 39(2), 129-140, 2004.

PORTER, M. Vantagem competitiva: criando e sustentando um desempenho superior. Rio de Janeiro: Campus, 1992.

SACHS, I. Caminhos para o desenvolvimento sustentável. Editora Garamond, 2002.

SCHUMPETER, J. A. The theory of economic development. New York, Oxford University Press, 1961 (publicado originalmene em 1934).

SENAI/DN, SESI/DN. Edital SENAI SESI de Inovação. Disponível em: < http://www.senai.br/editalinovacao>. Acesso em: 2010.

Rover S, Borba J. A., Borgert, A. Como as empresas classificadas no Índice de Sustentabilidade Empresarial (ISE) evidenciam os custos e investimentos ambientais? Custos e @gronegócio, 2008.

UFRJ, PROTEC, Avaliação dos resultados e sugestões de aperfeiçoamento do programa SENAI de inovação (2004-2007), Rio de Janeiro, 2010.

YIN, R. K. Case Study research - design and methods. Sage Publications Inc., USA, 1989.

\section{Dados dos autores:}

\section{Nome completo: Alysson Andrade Amorim}

Filiação institucional: SENAI/DN - Serviço Nacional de Aprendizagem Industrial / Aluno do curso de mestrado de administração do centro Universitário UNIEURO

Departamento: Unidade de Inovação e Tecnologia

Função ou cargo ocupado: Analista de Desenvolvimento Industrial

Endereço completo para correspondência: Quadra 105, lote 02, apto 401, Bloco B, Residencial

Flores do Ipê - Águas Claras - DF

Telefones para contato: 6181676157

e-mail:alys_br@yahoo.com.br

Nome completo: Hermes de Andrade Junior 
Filiação institucional: Centro Universitário - UNIEURO

Departamento: Mestrado de Administração - Comitê de Ética

Função ou cargo ocupado: Professor e pesquisador

Endereço completo para correspondência (bairro, cidade, estado, país e CEP): Condomínio RK,

Conjunto Antares, Quadra B, Casa 14, CEP.: 73017-010

Telefones para contato: 6184842942

e-mail: respeamb@gmail.com

Enviado em: 11/12/2010

Aprovado em: 28/09/2011 